\title{
KINETIC APPROACH OF THE DEPOSITION OF SILICON CARBIDE BASED FILMS OBTAINED BY PACVD
}

\author{
W. ZHANG, M. LELOGEAIS and M. DUCARROIR \\ IMP-CNRS, Université de Perpignan, 52 avenue de villeneuve, \\ $F-66860$ Perpignan cedex, France
}

\begin{abstract}
Silicon carbide deposition in an inductively coupled RF plasma reactor using tetramethysilane(TMS)/argon mixtures was carried out on steel substrates in a restricted range of experimental parameters. A kinetic approach in the pressure range of $0.7-2.4 \mathrm{kPa}$ is made to correlate the deposition rate of silicon carbide with plasma parameters. A "global" or "effective" concept has been emphasized. The main contribution of TMS dissociation in the present pressure range is assumed to the excited Ar(ion and metastable atom)-TMS molecule reactions rather than the primary electron-TMS reactions. A simple analytical expression for deposition rate is deduced which provides a good fit with experiments.
\end{abstract}

\section{I.-INTRODUCTION}

Plasma-assisted chemical vapor deposition(PACVD) is one of the most popular methods to synthesize thin films or coatings. In a PACVD process, the film forming elements are injected into the reactor as gases. The plasma dissociates the stable molecules into reactive radicals or ions which condense on surfaces and form good quality films at temperatures which are significantly lower than those used in thermal CVD. This ability to deposit useful thin films or coatings at lower temperatures is one of the major advantages of PACVD in microelectronic processing and surface protective applications. Other advantages, such as reasonable deposition rate, good adhesion, wide range of products and the control of film properties warrant further industrical applications of this technique.

Nevertheless, PACVD is probably the most complex of all the plasma-based surface processing technologies and there exists relatively little detailed understanding. Very little is known about the nature and relative abundances of the species arriving at the growing film and the parameter space in PACVD is very complex. Needless to say, 
process development is, by necessity, largely empirical.In PACVD the plasma is the key factor to influence the deposition rate and the film composition. Most radicals react with surfaces and consequently the film composition is largely determined by the relative fluxes of all the various film-forming species; none of which are known with any certainty. Energetic ion bombardment of the growing film has a large influence on films deposited by PACVD but again the mechanistic understanding is missing. Nevertheless, studies of detailed models of glow discharge chemical reactions are developing and increasing/1-7/. The effective use of detailed simulations depends strongly upon establishing the range of validity of the model. This requires experimental verification of the model predictions. Obviously, the more detailed and extensive the experimental measurements are, the greater the range and depth of model verification. This is why recent advances in plasma diagnostics are so important for meaningful progress in detailed modelling/8-17/.

We have recently proposed a simplified model to interpret the experimental phenomena in silicon carbide deposition from an inductively coupled RF discharge ( $2 \mathrm{MHz}$ ) using tetramethylsilane (TMS) and argon mixtures/18/. Electron-TMS molecule first-order reactions were assumed to be responsible for the dissociation of TMS molecules. In the experimental conditions explored (pressure range 100-700 $\mathrm{Pa}$ ) the model predictions are in good agreement with the experimental data. The goal of this work is to experimentally and theoretically investigate the relationship of deposition rate and plasma parameters at higher pressures $(\geq 700 \mathrm{~Pa}$ ). To extend the argurment of the low pressure model to the higher pressure case, the differences between the high and low pressure plasmas are examined and a modification is made.

\section{II.-EXPERIMENTAL}

The experimental set-up used in the present work has been described previously/18,19/. The deposition of silicon carbide coatings was performed in a cold-wall, inductively coupled vertical reactor. The plasma reactor consisted of a silica tube with an inner diameter of $28 \mathrm{~mm}$ and a length of $300 \mathrm{~mm}$. Silicon carbide coatings were deposited on polished steel substrates (with 1 micron diamond paste). The substrate (4135 type steel) of $16 \mathrm{~mm}$ in diameter and $6 \mathrm{~mm}$ in thickness was mounted vertically on the holder by machine screws. The substrate temperature was measured by a thermocouple which was embedded in the steel substrate kept at ground potential. The glow discharge was generated by a $2 \mathrm{MHz}$ RF generator which was connected to a water-cooled 8-turn coil outside the silica tube.

In the set of experiments to be reported here both the substrate temperature and RF voltage were maintained constant, i.e. $873 \mathrm{~K}$ and $2.7 \mathrm{kV}$, respectively. The reaction 
pressure was controlled by a throttle valve and measured with an absolute pressure gauge. The gas feed rates were regulated by mass flow controllers. The reactor was evacuated by a mechanical pump. The purities of the reactant sources were respectively 99.9\% for TMS $\left[\mathrm{Si}\left(\mathrm{CH}_{3}\right)_{4}\right]$ and $99.99 \%$ for Ar, and no further purification was made. In these conditions the coatings are constituted by a mixture of $\mathrm{SiC}$ and free $\mathrm{Si}$, leading to a global ration of $\mathrm{Si} / \mathrm{C}$ ranging from 1-1.25.

\section{III.-THEORY}

Following the guideline of our previous lower pressure model/18/, the present higher pressure approach emphasizes a "global" or "effective" concept. We made the following assumptions and approximations regarding the reactor and its performance:

(1). the main contribution of TMS dissociation (dissociation and dissociative ionization) in the discharge is due to the excited Ar(ion and metastable atom)-TMS molecule reaction in the plasma luminous zone near the substrate.

(2). the temperature, composition, pressure, and spatial distribution of electron density and energy are spatially uniform in the plasma luminous zone.

(3). any change in the number of moles of gas passing through the reactor that might arise from the reaction stoichiometry is neglected. This assumption may be considered as the reactant(TMS) is highly diluted by argon (TMS: $\sim 10 \%$ ). So there will be only a small change in the total number of moles of gas crossing the reactor.

The major difference with the previous lower pressure model is that the main reaction responsible for the TMS dissociation in the higher pressure model is assumed to the excited $\operatorname{Ar}$ (ion and metastable atom)-TMS molecule reaction rather than primary electron-TMS reactions. In relation with this assumption, it is worthwhile to mention the experimental observations of glow pictures in different pressures which may be helpful to understanding the plasma processes.

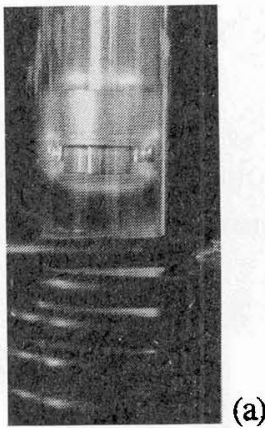

Fig.1 Plasma regions formed around the grounded substrate in an inductive RF plasma of $10 \%$ TMS-90\% Ar at three pressures: (a) 100Pa; (b) $500 \mathrm{~Pa}$ and (c) $1000 \mathrm{~Pa}$. 
As shown in Fig.1, at lower pressure $(100 \mathrm{~Pa})$, the luminosity of the plasma zone occurs almost in the whole volume extending from the coil up to substrate; in constrast, at higher pressure $(1000 \mathrm{~Pa})$ the glow becomes more luminous and restricted to the vicinity of the substrate, and spreads over it. This results in an increased deposition rate on the substrate with a simultaneous drastic reduction of the observed deposition on the reactor wall. Similar experimental phenomena have also been observed by Linger $/ 20 \%$. It is believed $/ 20,21 /$ that at these higher presssures the temperatures of the particles tend to equilibrate considerably lowering the electron temperatures, and recombination increases more rapidly than ionization reducing the electron concentration in the plasma bulk. This can explain the decreased deposition on the wall.

The existence of two distinct regimes ( $\alpha$ and $\gamma$ ) has been noted by Levitskii/22/ and Godyak and Khanneh/23/. In the $\gamma$ regime of the RF discharge, electron emission from electrode( $\gamma$ processes) is playing an essential role in the breakdown and the maintenance of a discharge, as in the glow discharge case. In constrast with this, in the $\alpha$ regime, the surface phenomena are not important and electron generation is determined by bulk ionization ( $\alpha$ processes). The RF discharges in the present conditions seem to fall in the $\gamma$ regime. The main reactions in this zone are assumed to be:

$$
\begin{array}{ll}
\mathrm{e}_{\mathrm{s}}^{-}+\mathrm{Ar} \rightarrow \mathrm{Ar}^{*(+)}+(2) \mathrm{e}^{-} & k_{\mathrm{Ar}} \\
\mathrm{Ar}^{*(+)}+\mathrm{TMS} \rightarrow \mathrm{Ar}+\mathrm{R}_{1}+\mathrm{R}_{2}+\ldots & k_{2}
\end{array}
$$

where $e_{s}^{-}$denotes the secondary electrons emitted from the substrate, $\mathrm{Ar}^{*(+)}$ denotes the excited Ar (metastable particle or positive ion), $R_{i}$ denotes the fragments coming from TMS dissociation.

The time and space averaged density of TMS molecules in the discharge can be estimated by solving the following conservation equations:

$$
\begin{aligned}
& \frac{\mathrm{n}_{\mathrm{TMS}}}{\tau}-\mathrm{k}_{2} \cdot \mathrm{n}_{\mathrm{Ar}} *(+) \cdot \mathrm{n}_{\mathrm{TMS}}-\frac{\mathrm{n}_{\mathrm{TMS}}}{\tau}=0 \\
& \mathrm{k}_{\mathrm{Ar}} \cdot \mathrm{n}_{\mathrm{e}_{\mathrm{S}}} \cdot \mathrm{n}_{\mathrm{Ar}}-\mathrm{k}_{2} \cdot \mathrm{n}_{\mathrm{Ar}} *^{(+)} \cdot \mathrm{n}_{\mathrm{TMS}}-\frac{\mathrm{n}_{\mathrm{Ar} *(+)}}{\tau}=0 \\
& \frac{\mathrm{n}_{\mathrm{Ar}}{ }^{\circ}}{\tau}-\mathrm{k}_{\mathrm{Ar}} \cdot \mathrm{n}_{\mathrm{e}_{\mathrm{S}}} \cdot \mathrm{n}_{\mathrm{Ar}}+\mathrm{k}_{2} \cdot \mathrm{n}_{\mathrm{Ar}} *(+) \cdot \mathrm{n}_{\mathrm{TMS}}-\frac{\mathrm{n}_{\mathrm{Ar}}}{\tau}=0
\end{aligned}
$$

where $n_{i}{ }^{\circ}$ and $n_{i}$ are respectively the densities of particle $i$ without and with plasma, $\tau$ is the residence time of the gas flowing through the plasma volume, $\mathrm{k}_{\mathrm{Ar}}$ and $\mathrm{k}_{2}$ are the reaction constants of reactions (1) and (2), respectively.

It is known that the energy of the secondary electrons could be quite high, e.g., $35 \mathrm{eV}$ 124/. Therefore, the excitation of Ar by these energetic secondary electrons may be effective. In this case, we assume $\mathrm{n}_{\mathrm{Ar} \mathrm{r}^{*(+)}} \approx \mathrm{n}_{\mathrm{Ar}}{ }^{\circ}$, thus 


$$
\mathbf{n}_{\mathrm{TMS}}=\frac{\mathrm{n}_{\mathrm{TMS}}{ }^{\circ}}{\mathrm{k}_{2} \cdot \mathrm{n}_{\mathrm{Ar}}{ }^{\circ} \cdot \tau+1}
$$

The dissociation degree of TMS $\alpha$ can be given by:

$$
\alpha=\left[1+\left(\mathrm{k}_{2} \cdot \mathrm{n}_{\mathrm{Ar}}{ }^{\circ} \cdot \tau\right)^{-1}\right]^{-1}
$$

Taking into account the relations of the residence time $\tau$ and $\mathrm{n}_{\mathrm{Ar}}{ }^{\circ}$ with the plasma parameters, we obtain an expression of the TMS dissociation degree as a function of plasma parameters:

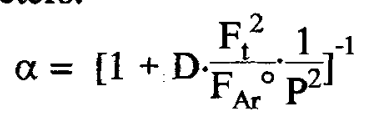

where

$$
\mathrm{D}=\frac{\mathrm{P}^{\circ} \cdot \mathrm{k}_{\mathrm{B}} \cdot \mathrm{T}}{\mathrm{k}_{2} \cdot \mathrm{V}}
$$

and where $P$ and $P^{\circ}$ are respectively reactor and ambient pressure, $V$ is plasma volume, $k_{B}$ is Boltzmann constant, $T$ is gas temperature, $F_{A r}^{\circ}$ and $F_{t}$ are the input Ar flow rate and total flow rate, respectively.

At this level, we know the number of decomposed TMS molecules for a given experimental condition. The decomposition of these TMS molecules may produce many kinds of active species such as excited neutrals, free radicals and ions. The decomposition of one mole of TMS [Si( $\left.\left.\mathrm{CH}_{3}\right)_{4}\right]$ will produce $\mathrm{d}$ mole(s) of active species which are responsible for the silicon carbide coating deposition. The number of moles of the precursors passing through the cross section where the substrate is positioned per unit time and area is given by

$$
\frac{1}{\mathrm{~A}} \cdot \frac{\mathrm{dm}}{\mathrm{dt}}=\mathrm{d} \cdot \frac{\mathrm{F}_{\mathrm{TMS}}{ }^{\circ} \cdot \alpha}{\mathrm{A} \cdot \mathrm{V}^{\circ}}
$$

where $\mathrm{F}_{\mathrm{TMS}}{ }^{\circ}$ is the input TMS flow rate at standard condition, $\mathrm{A}$ is the cross-section area of the reactor tube, $\mathrm{V}^{\circ}$ is the gas molar volume at standard conditions.

If we use the overall sticking coefficient $\beta$ to describe the overall surface reaction rate, we obtain the silicon carbide deposition rate $R\left(\mathrm{~nm} \cdot \mathrm{s}^{-1}\right)$ :

$$
R=\beta \cdot \mathrm{d} \cdot 10^{7} \cdot \frac{\mathrm{M}_{\mathrm{Si}-\mathrm{C}} \cdot \mathrm{F}_{\mathrm{TMS}}{ }^{\circ} \cdot \alpha}{\rho_{\mathrm{Si}-\mathrm{C}} \mathrm{A} \cdot \mathrm{V}^{\circ}}=\mathrm{B} \cdot \mathrm{F}_{\mathrm{TMS}} \cdot\left[1+\mathrm{D} \cdot \frac{\mathrm{F}_{\mathrm{t}}^{2}}{\mathrm{~F}_{\mathrm{Ar}}} \cdot \frac{1}{\mathrm{P}^{2}}\right]^{-1}
$$

with $\quad B=\beta \cdot d \cdot 10^{7} \cdot \frac{M_{S i-C}}{\rho_{S i-C} \cdot A \cdot V^{\circ}}$

where $\mathrm{M}_{\mathrm{Si}-\mathrm{C}}$ is the molecular weight of the silicon carbide coating $\left(\mathrm{g} \cdot \mathrm{mol}^{-1}\right), \rho_{\mathrm{Si}-\mathrm{C}}$ its mass density $\left(\mathrm{g} \cdot \mathrm{cm}^{-3}\right)$. Though the deposits exhibit a composition variation $(1<\mathrm{Si} / \mathrm{C}<1.25)$ $/ 19 /$, this latter one is not taken into account because its effect on the $\mathrm{M}_{\mathrm{Si}-\mathrm{C}} / \rho_{\mathrm{Si}-\mathrm{C}}$ ratio is negligible. 
Assuming that the value of B is constant in the experimental range used, equation (11) gives out a very simple analytical expression for the silcon carbide deposition rate correlated with the plasma parameters in the high pressure range.

\section{IV.-RESULTS AND DISCUSSIONS}

The fitted kinetic parameters in deposition rate expression [eqn.(11)] are the values B and $\mathrm{D}$. They were determined from a least mean squares fit of the experimental data. The values we obtained are:

$$
\mathrm{B}=6.0 \cdot 10^{-5} \mathrm{~cm}^{-2} \text { and } \mathrm{D}=7.9 \cdot 10^{6} \mathrm{~Pa}^{2} \cdot \mathrm{s} \cdot \mathrm{cm}^{-3}
$$

From eqn.(9), if the plasma volume is given, we can easily calculate the rate constant of $\mathrm{Ar}^{*(+)}$-TMS molecule reaction [reaction (2)] $\mathrm{k}_{2}$. In the pressure range examined $(0.7-$ $2.4 \mathrm{kPa}$ ), we observed that the luminous plasma layer had a thickness of 1-2 mm. Therefore we get $\mathrm{k}_{2} \approx(2.5-5) \cdot 10^{-16} \mathrm{~cm}^{3} \cdot \mathrm{s}^{-1}$. The reaction constant of the electron -TMS molecule reactions was given by: $\mathrm{k}_{1}=32 \cdot \mathrm{P}^{-0.48}\left(\mathrm{~s}^{-1}\right) / 18 /$. At a pressure of $700 \mathrm{~Pa}$, we find $\mathrm{k}_{2} \cdot \mathrm{n}_{\mathrm{Ar}}{ }^{\circ}\left(11-22 \mathrm{~s}^{-1}\right)>>\mathrm{k}_{1}\left(1.4 \mathrm{~s}^{-1}\right)$. This confirms that the assumption (1) for the higher pressure range is reasonable. The other kinetic parameter $B$ is $6.0 \cdot 10^{-5} \mathrm{~cm}^{-2}$ for higher pressures and $1.3 \cdot 10^{-5} \mathrm{~cm}^{-2}$ in the low pressure domain, respectively. In our approach, for simplicity, we have assumed that B is constant in each of the two pressure domains. But it should be noted that the value of B depends upon the gas phase plasma physics and chemistry, and the environment of the gas-surface interface. For example, the bombardment of ions on the substrate can greatly influence the sticking coefficient, and through that the B value. The differences between the high and low pressure plasmas are evident in Fig.1.

Using eqn.(11) and the obtained kinetic parameters [eqn.(13)], one can calculate the deposition rate of silicon carbide for the given conditions. Figures 2-4 show a comparison of the calculations (continuous dashed line) and experimental data as a function of reaction pressure, TMS flow rate and total flow rate. Fig. 2 shows the dependence of deposition rate on reaction pressure at a TMS ratio of $10 \%$ for two total flow rates $1.4 \mathrm{STP} \mathrm{cm}^{3} \cdot \mathrm{s}^{-1}$ and $0.56 \mathrm{STP} \mathrm{cm}^{3} \cdot \mathrm{s}^{-1}$, respectively. In the pressure range investigated, the deposition rate increases continuously with increasing pressure, more obviously as total flow rate increases. Fig. 3 displays the relationship of deposition rate versus TMS flow rate at a reaction pressure $1.2 \mathrm{kPa}$ and a total flow rate of 1.4 STP $\mathrm{cm}^{3} \cdot \mathrm{s}^{-1}$. The linear relation from the model prediction is well substantiated by experiments. Fig. 4 shows the correlation between depositon rate and total flow rate for a given pressure $1.2 \mathrm{kPa}$ and a constant TMS ratio $10 \%$. The deposition rate increases with the increase of total flow rate, but a saturation is observed at higher total flow rates. All these figures show that the model gives a dependence on reaction pressure, 
TMS flow rate and total flow rate which in agreement with the experiments carried out. In Fig.5 we provide a comparison of model predictions and measured data for all experiment runs which we have performed in the pressure range of $0.7-2.4 \mathrm{kPa}$. The correlation shown in Fig.5 is clearly linear, and the slope and intercept are respectively one and zero. As follows from the comparison of calculations and experiments, in spite of a number of simplifying assumptions, the theoretical approach describes satisfactorily the experiments.

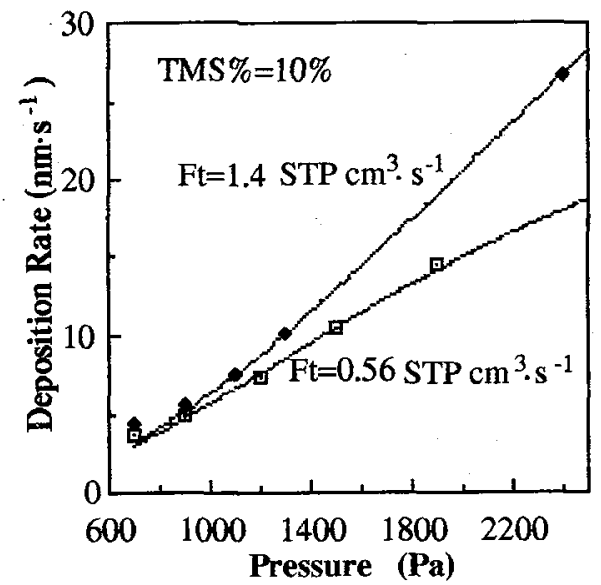

Fig.2 Calculated and measured deposition rates vs. reaction pressure at constant TMS ratio and total flow rates 0.56 and $1.4 \mathrm{STP} \mathrm{cm}^{3} \cdot \mathrm{s}^{-1}$, respectively.

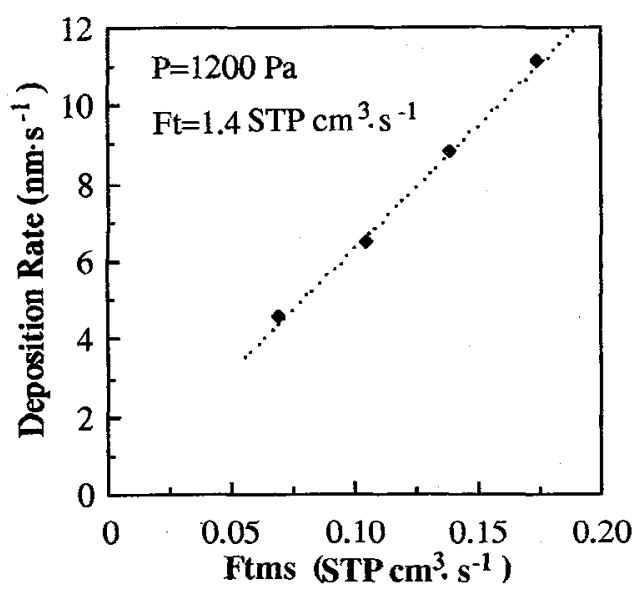

Fig. 3 Calculated and measured deposition rates vs. TMS flow rate at constant pressure and total flow rate.

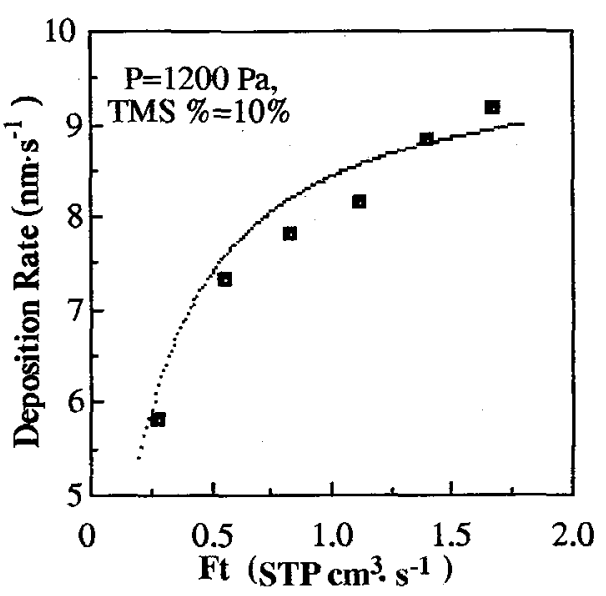

Fig.4 Calculated and measured deposition rates vs. total flow rate at $1.2 \mathrm{kPa}$ and $10 \%$ TMS.

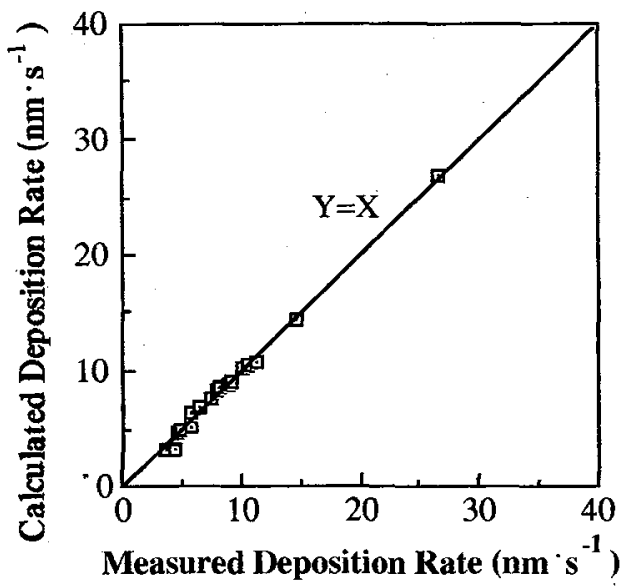

Fig.5 Comparison of model predictions and experimental data for all runs of experiments performed. 


\section{V.-CONCLUSIONS}

Silicon carbide deposition in a cold-wall, inductively coupled $\mathrm{RF}(2 \mathrm{MHz})$ plasma reactor using tetramethysilane and argon mixtures was carried out on a steel substrate. In the investigated pressure range $(700 \mathrm{~Pa} \leq \mathrm{P} \leq 2.4 \mathrm{kPa})$, we have derived a simple analytical expression to describe the variation of the deposition rate at constant temperature as a function of reaction pressure and gas flow rates. This was established on the assumption that the main reactions responsible for the TMS dissociation are assumed to be the excited $\operatorname{Ar}$ (ion and metastable atom)-TMS molecule reactions rather than the primary electron-TMS reactions. These latter reactions tend to prevail at lower pressures. The calculated trends of deposition rate correlate well with the experiments.

\section{ACKNOWLEDGMENTS}

The French Foreign Office is acknowledged for its financial support through a grant.

\section{REFERENCES}

11/ BOEUF J.-P., Phys. Rev. A 36 (1987) 2782.

12/ BARNES M.S., COLTER T.J., and ELTA M.E., J. Appl. Phys. 61 (1987) 81.

13/ GRAVES D.B. and JENSEN K.F., IEEE Trans. Plasma Sci. PS-14 (1986) 78.

14/ GRAVES D.B., J. Appl. Phys. 62 (1987) 88.

15i RICHARDS A.D.,THOMPASON B.E.,and SAWIN H.H., Appl. Phys. Lett. 50 (1987) 492.

16l GOGOLIDES E., NICOLAI J.P., and SAWIN H.H., J. Vac. Sci. Technol. 7 (1989)1001.

171 MEYYAPPAN E. and KRESKOVSKY J.P., J. Appl. Phys. 68 (1990) 1506.

18/ KOKUBO T., TOCHIKUBO F., and MAKABE T., J. Phys. D 22 (1989) 1281.

19/ MUCHA J.A., FLAMM D.L., and IBBOTSON D.E., J. Appl. Phys. 65 (1989) 3448.

/10/ COBURN J.W. and CHEN M., J. Appl. Phys. 51 (1980) 3134.

/11/ ROTH R.M., SPEARS K.G., and WONG G., Appl. Phys. Lett. 45 (1984) 28.

1121 GOTTSCHO R.A. and MILLER T.A., Pure and Appl. Chem. 56 (1984) 189.

/13/ FARROW L.A., J. Chem. Phys. 82 (1985) 3625.

114l ZHANG W. and CATHERINE Y., Surf. Coat. Technol., in press.

115/ ZHANG W. and CATHERINE Y., Plasma chem. Plasma Process., in press.

/16l COBURN J.W., Thin Solid Films, 171 (1989) 65.

/17/ DOWNEY S.W., MITCHELL A., and GOTTSCHO R.A., J. Appl. Phys. 63 (1988) 5280.

118/ ZHANG W., LELOGEAIS M., and DUCARROIR M., submitted to J. Electrochem. Soc.

/19/ LELOGEAIS M. and DUCARROIR M., Thin Solid Films, 197 (1991) 257.

120/ LINGER K.R.,Ion Plating \& Allied Technol.,Conf.Proc. Edingbourgh,1977, p.223.

121/ HELLUND E.J., The Plasma State, Reinhold Publishing Corp., 1961.

122/ LEVITSKII S.M., Sov. Phys.-Tech. Phys., 2 (1957) 887.

123/ GODYAK V.A. and KHANNEH A.S., IEEE Transactions on Plasma Science, PS-14 (1986) 112.

24I KUSHNER M.J., J. Appl. Phys. 54 (1983) 4958. 